${ }^{1}$ Orthodontics Program. UniCIEO University, Bogotá, Colombia.
Corresponding author:

Dr. Judith Patricia Barrera Chaparro, Assistant professor, Orthodontic Department, UniCIEO University. Cra. 5 \#118-10, Bogotá, Colombia. e-mail:.jp.barrera@unicieo.edu.co Phone: (+57) 3002123863

Received: October 27, 2020 Accepted: January 13, 2021

\section{Modified short version of the oral health impact profile for patients undergoing orthodontic treatment}

\author{
Judith Patricia Barrera-Chaparro1,* (iD), Sonia Patricia \\ Plaza-Ruíz ${ }^{1}$ (iD), Tania Camacho-Usaquén ${ }^{1}$ (ID), Jairo \\ Andrés Pasuy-Caicedo ${ }^{1}$ iD, Ada Katherine \\ Villamizar-Rivera ${ }^{1}$ (iD)
}

Aim: To derive and validate a short version of the Oral Health Impact Profile (OHIP) in Spanish to measure oral health quality of life (OHRQoL) for subjects wearing fixed orthodontic appliances. Methods: Cross-sectional study (data for sensitivity to change analysis were collected longitudinally). The data of 400 subjects (27.34 years, SD 11.66 years, 231 women, and 169 men) were used to develop a short-form instrument, and the data of 126 other subjects (25.95 years, SD 12.39 years, 62 women, and 64 men) were used for its validation. The original OHIPs were translated into Spanish using an iterative forward-backward sequence. After face and content validity were evaluated by an expert committee, an exploratory factorial analysis (EFA) was used to derive the Spanish short-form instrument (OHIP-S14 Ortho). To validate the OHIP-S14 Ortho, validity (content validity assessed by EFA, construct validity assessed by confirmatory factor analysis (CFA), discriminative validity assessed by the Kruskal-Wallis test, and reliability (internal consistency assessed by Cronbach's a test-retest, and inter-observer reliability assessed by correlation coefficients) were evaluated. Sensitivity to change and usefulness of the scale were also evaluated. Results: The OHIP-S14 Ortho included only six of the items in Slade's original OHIP-14 short-form. A two-factor structure with adequate discriminative validity was found. High internal consistency $(a=0.912)$, excellent inter-observer (Lin's correlation $=0.97 \pm 0.011$; rho $=0.97$ ), test-retest agreement (Lin's correlation $=0.80 \pm 0.059$ ) and adequate sensitivity to change were also found. Conclusions: The OHIP-S14 Ortho is a valid and reliable instrument to measure OHRQoL in Spanish-speaking patients with fixed orthodontic appliances.

Keywords: Quality of Life. Reproducibility of results. Orthodontic appliances. 


\section{Introduction}

Oral health-related quality of life (OHRQoL) is multidimensional and impacts the functional, psychological, and social aspects of daily life'. Individuals seek orthodontic treatment mainly because they are dissatisfied with their appearance, dental malposition, deformity of the teeth, or spaces between them; therefore, OHRQoL after orthodontic treatment tends to improve ${ }^{3}$. However, wearing fixed orthodontic appliances can cause pain and difficulty with eating, speaking, or smiling, and the OHRQOL seems to deteriorate during orthodontic treatment ${ }^{4,5}$.

The most widely used instrument to measure OHRQoL is the Oral Health Impact Profile (OHIP), which was proposed by Slade and Spencer ${ }^{6}$. The long-form of this instrument has 49 items (OHIP-49), the short form has 14 items (OHIP-14), and the instrument covers seven dimensions (i.e., functional limitation, physical pain, psychological discomfort, physical disability, psychological disability, social disability, and handicap). A long questionnaire may not be feasible to administer in clinical settings because it has a high cost of administration and data provision, takes a long time to complete and score, and causes a burden on the respondent, which may lead to the exclusion of a substantial proportion of respondents or problems arising from the need to impute missing data ${ }^{7}$. Because of respondents' different cultural backgrounds, short forms of the OHIP-49 have been derived and validated in different languages and countries ${ }^{8-13}$, and most of them were validated in an adult population with oral health or oral rehabilitation needs.

Although the World Health Organization $(\mathrm{WHO})^{14}$ does not consider malocclusion an illness and most patients continue to have good oral health during orthodontic treatment, wearing fixed appliances may affect aspects of a patient's quality of life in different ways when compared to patients who have caries, tooth loss, or periodontal disease. Pain is a near pervasive unpleasant experience encountered during orthodontic treatment. Numerous authors ${ }^{15-18}$ have linked orthodontic treatment to the experience of pain, finding that orthodontic patients are most likely to experience increased levels of pain for one to three days following the placement of their appliance and subsequent adjustment visits. To date, to the best of our knowledge, a short form of OHIP has not been developed for patients with orthodontic treatment. For this reason, the present research study aims to derive and validate a short form of the OHIP-49 (OHIP-S14 Ortho) in Spanish to measure OHRQoL in patients wearing orthodontic appliances.

\section{Materials and Methods}

This was a cross-sectional study. However, the data for sensitivity to change analysis was collected longitudinally. The study included individuals who were wearing fixed orthodontic appliances provided by UniCIEO University in Bogotá, Colombia, between January 2016 and November 2017. This study was approved by the UniCIEO University Ethics Committee. All participants and parents/guardians of minors signed the informed consent form. The research was conducted in full accordance with the World Medical Association Declaration of Helsinki. 
From 1,151 eligible subjects during the study period, 400 were chosen by non-probabilistic sampling (for convenience) for the OHIP short version derivation. Additionally, another 126 subjects were chosen for the OHIP-S14 Ortho validation. The sample size was estimated using the criterion recommended by Streiner ${ }^{19}$, which recommends that 5 to 10 subjects per variable be included in the sample. For the reliability assessment, the calculation of the sample size for the intraclass correlation coefficient (ICC) was considered to achieve an ICC equal to or greater than 0.6, a confidence interval $(\mathrm{Cl})$ of $95 \%(\mathrm{a}=0.05)$ and $90 \%$ power was calculated, resulting in a sample size of 25 subjects.

A total of 126 subjects were included in the internal consistency analysis. Randomly (simple random sampling) selected were 40 for the test-retest reliability analysis, 30 for the inter-observer agreement analysis, 25 for the sensitivity to change analysis, and 50 for the analysis of the instrument's usefulness. The inclusion criteria involved patients who had active orthodontic treatment with fixed orthodontic appliances, who were $\geq 12$ years old, and whose native language is Spanish. Patients with a physical or mental disability that hindered administration of the survey and patients with other oral health conditions (e.g., cavities, muscle pain, periodontal pain) were excluded.

The OHRQoL was measured by the OHIP-49 scale 6 . The questionnaire was self-administered by the participants on paper, except for the assessments related to the sensitivity to change (the scale was administered at three time points: $\mathrm{TO}=$ immediately before bracket placement, $\mathrm{T} 1=24$ to 48 hours after bracket placement, and T2=2 weeks after bracket placement), interobserver agreement (two observers administered the instrument in 5-minute intervals) and test-retest reliability (application of the instrument repeatedly, at two time points separated by 24 to 48 hours), which were completed through telephone interviews by three researchers previously trained in the implementation of the instrument (Kappa: 0.88). The time intervals were chosen because the changes in the short time of the status of patients wearing fixed orthodontic appliances, due to the activation of the devices, the type of arch, etc.

Demographic variables (i.e., sex; age) were recorded at the time that the questionnaire was applied. Two clinical variables were retrieved from clinical records: the time having worn the fixed appliances at survey's administration, in days, and time since the last orthodontic adjustment visit. Discriminative validity was evaluated by a Visual Analogue Scale for Pain (VAS Pain). Scores were assigned, with 0 corresponding to the absence of pain and 10 corresponding to the highest intensity of pain. The scores were categorized as mild (0 to 2 ), moderate (3 to 7 ), or intense (8 to 10). The time required to complete the questionnaire for both the long-form and the short-form was also recorded.

As recommended by $\mathrm{WHO}$, a systematic approach to translation and adaptation was conducted $^{20}$. It requires five steps: forward-translation, expert panel discussion, backward translation, a pre-test, a cognitive briefing, and a consensus on the final version. The English version of the OHIP-496 was translated into Spanish by four bilingual professionals (three Colombian and one British professional) using an iterative forward-backward sequence. Four orthodontists and four orthodontic patients assessed the face validity (i.e., Does the test "look like" a measure of the construct of interest?) and content 
validity (i.e., Does the test contain items from the desired "content domain"?). A subsequent preliminary fit test was performed with 10 orthodontic patients.

\section{Statistical Analysis}

The statistical analysis was performed with STATA14 software (version 14.0; StataCorp, College Station, Tex). The statistical analysis process was conducted in consecutive steps as follows:

1. OHIP-S14 Ortho Derivation: To derive a subgroup of 14 questions, an exploratory factor analysis (EFA) was used (assumptions previously verified: sphericity by using Bartlett's sphericity test $(P<0.05)$ and sampling adequacy by using the Kaiser-Meyer-Olkin $(\mathrm{KMO})>0.80)$. The factors to be extracted were determined by the percentage and variance explained (minimum of $80 \%$ ). The factor loads for each question were estimated to identify those that exceeded 0.4 , which was the cutoff point for moderate to high loads. Then, the items that presented the highest factor loads were chosen, and no more than two items of each conceptual dimension were included. To determine whether the removal of the individual items affected the internal consistency of the derived OHIP short version, an analysis using Cronbach's a coefficient was carried out.

\section{OHIP-S14 Ortho Validation}

\subsection{Validity of the OHIP-S14 Ortho:}

Content validity was evaluated by exploratory factor analysis (EFA). Construct validity was evaluated by confirmatory factor analysis (CFA) using the maximum likelihood method. The fit of a model was considered adequate when the ratio of the chi-squared value to the degrees of freedom $(\chi 2 / \mathrm{df})<2.0$, root mean square error of approximation (RMSEA) <0.10, comparative adjustment index (CFI) >0.90, Tucker-Lewis index (TLI) $>0.9$ and low values of the Akaike information criterion (AIC), Browne-Cudeck criterion and the Bayes information criterion (BIC) were obtained ${ }^{21}$. Discriminative validity was evaluated by comparing the OHIP-S14 Ortho with a VAS Pain categorized scale (mild, moderate, severe) by the Kruskal Wallis test.

\subsection{Reliability of the OHIP-S14 Ortho:}

Internal consistency was evaluated by the Cronbach's a coefficient. Intra-observer reliability (test-retest) was evaluated by Lin's concordance correlation coefficient. The inter-observer reliability was evaluated by the Spearman correlation coefficient and Lin's concordance correlation coefficient.

\subsection{Sensitivity to change:}

This was evaluated by comparing the measurements at T0, T1, and T2 by the Wilcoxon signed-rank test for paired samples.

Our approach to avoiding missing data was to maximize the data collection by explaining to participants the importance of their responses and motivating them to fill out the surveys. However, in the cases where missing data happened, a listwise deletion method was used. 


\section{Results}

The descriptive statistics of the samples are shown in Table 1. The sample to derivate the OHIP-S14 Ortho was composed of 400 subjects ( 27.34 years, SD 11.66, 231 women, and 169 men). Another sample of 126 subjects was used for its validation (25.95 years, SD 12.39, 62 women, and 64 men). The mean time spent wearing fixed appliances was $420.76(S D=331.46)$ days for the short version derivation sample and 146.167 (SD = 262.43) days for the OHIP-S14 Ortho validation sample.

The experts' panel removed three of the OHIP-49 questions from the questionnaire; two referred to edentulous patients (Q17 and Q18), and one (Q3: a tooth that does not look good) was redundant and confusing for orthodontic patients. This is because patients seeking orthodontic treatment perceive that crowded teeth do not look good. A modification in the questions related to time was also made; the text was modified to 1 month to match the orthodontic appointment interval.

Table 1. Demographic and clinical characteristics of the subjects

\begin{tabular}{|c|c|c|c|c|}
\hline & \multicolumn{2}{|c|}{$\begin{array}{l}\text { Sample for short version derivation } \\
\qquad(n=400)\end{array}$} & \multicolumn{2}{|c|}{$\begin{array}{l}\text { Sample for OHIP-S14 Ortho validation } \\
\qquad(\mathrm{n}=126)\end{array}$} \\
\hline \multicolumn{5}{|c|}{ Categorical variables } \\
\hline & $\mathrm{n}$ & $\%$ & $\mathrm{n}$ & $\%$ \\
\hline \multicolumn{5}{|l|}{ Sex } \\
\hline Male & 169 & 42.25 & 64 & 50.79 \\
\hline Female & 231 & 57.75 & 62 & 49.21 \\
\hline \multicolumn{5}{|l|}{ Age categorized } \\
\hline$<18$ years old & 71 & 17.75 & 33 & 26.19 \\
\hline$\geq 18$ years old & 329 & 82.25 & 93 & 73.81 \\
\hline \multicolumn{5}{|c|}{ Quantitative variables } \\
\hline & mean (sd) & median (min-max) & mean (sd) & median (min-max) \\
\hline \multicolumn{5}{|l|}{ Age } \\
\hline Total sample & 27.375 (11.633) & $24(12-66)$ & $26.055(12.440)$ & $22(12-66)$ \\
\hline$<18$ years old & $15.154(1.348)$ & $15(12-17)$ & $14.654(1.486)$ & $14.71(12-17)$ \\
\hline$\geq 18$ years old & 30.012 (11.177) & $26(18-66)$ & $30.101(12.097)$ & $26(18-66)$ \\
\hline $\begin{array}{l}\text { Time wearing fixed } \\
\text { appliances (days) }\end{array}$ & $420.76(331.46)$ & $364(1-1932)$ & $146.167(262.43)$ & $80.5(1-1334)$ \\
\hline $\begin{array}{l}\text { Time since the last } \\
\text { orthodontic adjustment } \\
\text { visit (days) }\end{array}$ & $28.81(14.03)$ & $28(7-84)$ & $32.18(25.09)$ & $28(0-112)$ \\
\hline OHIP-49 total score & $26.53(19.591)$ & $23(0-108)$ & - & - \\
\hline$<18$ years old & $21.452(14.974)$ & $19(0-64)$ & - & - \\
\hline$\geq 18$ years old & $27.626(20.304)$ & $23(0-108)$ & - & - \\
\hline OHIP-S14 Ortho total score & - & - & $10.849(9.138)$ & $9(0-45)$ \\
\hline$<18$ years old & - & - & $8.333(7.056)$ & $6(0-31)$ \\
\hline$\geq 18$ years old & - & - & $11.742(9.647)$ & $10(0-45)$ \\
\hline $\begin{array}{l}\text { VAS Pain total score } \\
\text { (scale } 10 \mathrm{~mm})\end{array}$ & - & - & $3.40(2.43)$ & $3(0-10)$ \\
\hline
\end{tabular}




\section{OHIP-S14 Ortho Derivation:}

EFA was performed after it was verified that the data met the assumptions (Bartlett's sphericity test $\left.\left(X^{2}=9808.468, P<0.0001\right), \mathrm{KMO}=0.911\right)$. Four factors were extracted by the percentage and variance explained (minimum of $80 \%$ ); the first had an eigenvalue of 13.06 , which accounted for $50.71 \%$ of the variance, and the four factors accounted for $80.34 \%$ of the variance (Table 2 ).

Table 2. Exploratory factor analysis OHIP-49 and OHIP-S14 Ortho. The factors were extracted by the percentage and variance explained (minimum of $80 \%$ ).

\begin{tabular}{lccccccc}
\hline OHIP-49 & & & \multicolumn{4}{c}{ OHIP-S14 Ortho } \\
\hline Factor & Eigenvalue & $\begin{array}{c}\text { \% of } \\
\text { variability }\end{array}$ & $\begin{array}{c}\text { \% of cumulative } \\
\text { variability }\end{array}$ & Factor & Eigenvalue & $\begin{array}{c}\text { \% of } \\
\text { variability }\end{array}$ & $\begin{array}{c}\text { \% of cumulative } \\
\text { variability }\end{array}$ \\
\hline $\mathbf{1}$ & 13.06 & 50.71 & 50.71 & 1 & 6.50 & 78.9 & 78.9 \\
\hline $\mathbf{2}$ & 3.6 & 13.98 & 64.69 & 2 & 1.02 & 12.4 & 91.23 \\
\hline $\mathbf{3}$ & 2.46 & 9.55 & 74.24 & & & & \\
\hline $\mathbf{4}$ & 1.57 & 6.1 & 80.34 & & & & \\
\hline
\end{tabular}

Table 3 shows the non-response item frequency, item prevalence (\% of responses corresponding to occasionally, fairly often, or very often), item severity (item mean), and the OHIP-S14 Ortho development procedure with the highest factorial load questions. EFA correlation loads greater than 0.4 were represented almost entirely by factor 1 , except for seven questions (Q2, Q11, Q12, Q25, Q44, Q45, Q48). The 14 items selected according to their factor loads were Q1, Q4, Q16, Q15, Q23, Q22, Q32, Q31, Q34, Q35, Q41, Q42, Q47, and Q46.

Internal consistency (Cronbach's a coefficient) for the OHIP-49 was in total of $a=0.93$ (Annex 1).

The comparison of the obtained questions of the OHIP-S14 Ortho with those of the OHIP-14 derived by Slade ${ }^{22}$ are shown in table 4. Only six items from Slade's original OHIP-14 version were included in the OHIP-S14 Ortho. OHIP S14- Ortho agreed in six questions with the original OHIP-14 short form.

Table 3. Prevalence, mean, exploratory factor analysis of OHIP long-form questions

\begin{tabular}{lcccc}
\hline Item and conceptual dimension & No response $\%$ & \% Prevalence & Mean & $\begin{array}{c}\text { General factor } \\
\text { load }\end{array}$ \\
\hline Functional limitation & & & & \\
\hline Q1 Difficulty chewing & 0 & 46.25 & 1.28 & $0.53^{\star}$ \\
\hline Q2 Difficulty pronouncing words & 0 & 17 & 0.6 & 0.4 \\
\hline Q3 Tooth that does not look good & $\cdot$ &. & $\cdot$ &. \\
\hline Q4 Affected appearance & 0.25 & 20 & 0.657 & $0.58^{*}$ \\
\hline Q5 Bad breath & 0 & 28 & 0.787 & 0.4 \\
\hline Q6 Worsened taste & 0.25 & 7.25 & 0.276 & 0.47 \\
\hline Q7 Stuck Food & 0.75 & 7.25 & 2.065 & 0.48 \\
\hline Q8 Digestion worsened & 0 & 5.75 & 0.255 & 0.45 \\
\hline
\end{tabular}




\begin{tabular}{|c|c|c|c|c|}
\hline \multicolumn{5}{|c|}{ Physical Pain } \\
\hline Q9 Pain in a wound mouth & 0 & 53 & 1.497 & 0.51 \\
\hline Q10 Discomfort in the jaw & 0.50 & 21 & 0.693 & 0.50 \\
\hline Q11 Headaches & 0 & 9 & 0.32 & 0.38 \\
\hline Q12 Sensitive teeth & 0.25 & 41 & 1.22 & 0.36 \\
\hline Q13 Pain in your teeth & 0.25 & 53 & 1.464 & 0.45 \\
\hline Q14 Pain in your gums & 0.25 & 24 & 0.819 & 0.47 \\
\hline Q15 Eating discomfort & 0.25 & 58 & 1.569 & $0.59 *$ \\
\hline Q16 Painful sites in the mouth & 0 & 45.5 & 1.28 & $0.62^{*}$ \\
\hline Q17 Unfitted dentures & . & . & . & . \\
\hline Q18 Uncomfortable dentures & . & . & . & . \\
\hline \multicolumn{5}{|c|}{ Psychological discomfort } \\
\hline Q19 Worried & 0 & 15 & 0.522 & 0.45 \\
\hline Q20 Self-conscious & 0 & 12 & 0.42 & 0.65 \\
\hline Q21 Unhappy & 0 & 7.25 & 0.23 & 0.60 \\
\hline Q22 Appearance of brackets & 0 & 14.25 & 0.485 & $0.67^{*}$ \\
\hline Q23 Tense & 0 & 13.75 & 0.455 & $0.66^{*}$ \\
\hline \multicolumn{5}{|c|}{ Physical disability } \\
\hline Q24 Speak badly & 0 & 15.75 & 0.545 & 0.49 \\
\hline $\begin{array}{l}\text { Q25 People do not understand } \\
\text { my words }\end{array}$ & 0 & 14.75 & 0.482 & 0.37 \\
\hline Q26 Less flavor in food & 0 & 8.25 & 0.307 & 0.51 \\
\hline Q27 Unable to brush your teeth & 0 & 35.5 & 1.04 & 0.48 \\
\hline Q28 Avoid eating & 0.25 & 61.25 & 1.697 & 0.53 \\
\hline Q29 Unsatisfactory diet & 0 & 17.5 & 0.547 & 0.54 \\
\hline Q30 Unable to eat & 0 & 17 & 0.597 & 0.61 \\
\hline Q31 Avoid smiling & 0.50 & 19.75 & 0.623 & $0.67^{\star}$ \\
\hline Q32 Discontinuing meals & 0 & 21.75 & 0.685 & $0.66^{*}$ \\
\hline \multicolumn{5}{|c|}{ Psychological disability } \\
\hline Q33 Interrupting sleep & 0 & 6.25 & 0.26 & 0.56 \\
\hline Q34 Upset & 0 & 17.25 & 0.55 & $0.72^{\star}$ \\
\hline Q35 Difficulty to relax & 0.75 & 2.5 & 0.325 & $0.70^{\star}$ \\
\hline Q36 Depressed & 0 & 3.75 & 0.147 & 0.62 \\
\hline Q37 Affected attention & 0 & 2.25 & 0.157 & 0.54 \\
\hline Q38 Ashamed & 0.25 & 11 & 0.383 & 0.69 \\
\hline \multicolumn{5}{|c|}{ Social disability } \\
\hline Q39 Avoid leaving & 0.50 & 2.75 & 0.131 & 0.58 \\
\hline Q40 Less tolerant with others & 0.25 & 3.25 & 0.15 & 0.52 \\
\hline Q41 Interacting with others & 0.25 & 3.75 & 0.15 & $0.61^{*}$ \\
\hline Q42 Irritable with others & 0.25 & 3.5 & 0.168 & $0.59 *$ \\
\hline Q43 Difficulty of working & 0.25 & 2.25 & 0.113 & 0.50 \\
\hline \multicolumn{5}{|c|}{ Handicap } \\
\hline Q44 General affected health & 0.25 & 1.25 & 0.078 & 0.31 \\
\hline Q45 Financial loss & 0.25 & 5.75 & 0.215 & 0.23 \\
\hline Q46 Enjoy company & 0.25 & 2.75 & 0.095 & $0.49 *$ \\
\hline Q47 Unsatisfactory life & 0.25 & 2.5 & 0.12 & $0.54^{*}$ \\
\hline Q48 Unable to operate & 0.25 & 0 & 0.03 & 0.34 \\
\hline Q49 Unable to work & 0.25 & 1.5 & 0.083 & 0.43 \\
\hline
\end{tabular}

* Highest factorial load questions (selected two for each dimension). 
Table 4. Comparison of OHIP-14 Original Slade questions and OHIP-S14 Ortho questions

\begin{tabular}{|c|c|c|c|c|}
\hline & & OHIP -14 (Original Slade) & & OHIP- S14 Ortho \\
\hline & & & & Question \\
\hline \multirow{2}{*}{$\begin{array}{l}\text { Functional } \\
\text { limitation }\end{array}$} & 2 & $\begin{array}{l}\text { Have you had trouble } \\
\text { pronouncing any words } \\
\text { because of problems with your } \\
\text { teeth, mouth or dentures? }\end{array}$ & 1 & $\begin{array}{l}\text { ¿En el último mes ha tenido dificultad para masticar } \\
\text { algún tipo de comida debido a sus brackets? } \\
\text { In the last month have you had difficulty chewing any } \\
\text { type of food because of your brackets? }\end{array}$ \\
\hline & 6 & $\begin{array}{l}\text { Have you felt that your } \\
\text { sense of taste has worsened } \\
\text { because of problems with your } \\
\text { teeth, mouth or dentures? }\end{array}$ & 4 & $\begin{array}{l}\text { ¿En el último mes ha tenido la sensación de que su } \\
\text { apariencia se ve afectada debido a sus brackets? } \\
\text { In the last month have you had the feeling that your } \\
\text { appearance is affected due to your brackets? }\end{array}$ \\
\hline hysical Pain & 9 & $\begin{array}{c}\text { Have you had painful aching in } \\
\text { your mouth? }\end{array}$ & 16 & $\begin{array}{l}\text { ¿En el último mes ha tenido sitios dolorosos en su } \\
\text { boca debido a sus brackets? } \\
\text { In the last month have you had painful sites in your } \\
\text { mouth because of your brackets? }\end{array}$ \\
\hline
\end{tabular}

15 uncomfortable to eat any

foods because of your teeth, mouth or dentures?

\begin{tabular}{|c|c|c|c|c|}
\hline & 15 & $\begin{array}{c}\text { Have you found it } \\
\text { uncomfortable to eat any } \\
\text { foods because of your teeth, } \\
\text { mouth or dentures? }\end{array}$ & 15 & $\begin{array}{c}\text { ¿En el último mes ha sentido incomodidad al comer } \\
\text { algunos alimentos debido a sus brackets? } \\
\text { In the last month have you felt discomfort when } \\
\text { eating some foods due to your brackets? }\end{array}$ \\
\hline \multirow{2}{*}{$\begin{array}{l}\text { Psychological } \\
\text { discomfort }\end{array}$} & 20 & $\begin{array}{l}\text { Have you been self-conscious } \\
\text { because of your teeth, mouth } \\
\text { or dentures? }\end{array}$ & 22 & $\begin{array}{c}\text { ¿En el último mes se ha sentido incomodo debido a } \\
\text { la apariencia de sus Brackets? } \\
\text { In the last month, have you felt uncomfortable due to } \\
\text { the appearance of your brackets? }\end{array}$ \\
\hline & 23 & $\begin{array}{l}\text { Have you felt tense because } \\
\text { of problems with your teeth, } \\
\text { mouth or dentures? }\end{array}$ & 23 & $\begin{array}{c}\text { ¿En el último mes se ha sentido tenso debido a } \\
\text { sus brackets? } \\
\text { In the last month, have you felt tense because of } \\
\text { your brackets? }\end{array}$ \\
\hline \multirow{2}{*}{$\begin{array}{l}\text { Physical } \\
\text { disability }\end{array}$} & 29 & $\begin{array}{l}\text { Has your diet been } \\
\text { unsatisfactory because of } \\
\text { problems with your teeth, } \\
\text { mouth or dentures? }\end{array}$ & 31 & $\begin{array}{c}\text { ¿En el último mes ha evitado sonreír debido a sus } \\
\text { brackets? } \\
\text { In the last month have you avoided smiling because } \\
\text { of your brackets? }\end{array}$ \\
\hline & 32 & $\begin{array}{l}\text { Have you had to interrupt } \\
\text { meals because of problems } \\
\text { with your teeth, mouth } \\
\text { or dentures? }\end{array}$ & 32 & $\begin{array}{l}\text { ¿En el último mes ha tenido que interrumpir sus } \\
\text { comidas debido a sus brackets? } \\
\text { In the last month you had to interrupt your meals } \\
\text { because of your brackets? }\end{array}$ \\
\hline \multirow{2}{*}{$\begin{array}{l}\text { Psychological } \\
\text { disability }\end{array}$} & 35 & $\begin{array}{l}\text { Have you found it difficult to } \\
\text { relax because of problems } \\
\text { with your teeth, mouth } \\
\text { or dentures? }\end{array}$ & 35 & $\begin{array}{c}\text { ¿En el último mes ha encontrado dificultad para } \\
\text { relajarse debido a sus brackets? } \\
\text { In the last month have you found difficulty relaxing } \\
\text { due to your brackets? }\end{array}$ \\
\hline & 38 & $\begin{array}{l}\text { Have you been a bit } \\
\text { embarrassed because of } \\
\text { problems with your teeth, } \\
\text { mouth or dentures? }\end{array}$ & 34 & $\begin{array}{c}\text { ¿En el último mes se ha sentido molesto debido a } \\
\text { sus brackets? } \\
\text { In the last month, have you felt upset due to } \\
\text { your brackets? }\end{array}$ \\
\hline \multirow{2}{*}{$\begin{array}{l}\text { Social } \\
\text { disability } \\
\text { social }\end{array}$} & 42 & $\begin{array}{l}\text { Have you been a bit irritable } \\
\text { with other people because } \\
\text { of problems with your teeth, } \\
\text { mouth or dentures? }\end{array}$ & 42 & $\begin{array}{l}\text { ¿En el último mes ha estado un poco irritable con } \\
\text { otras personas debido a sus brackets? } \\
\text { Have you been a bit irritable with other people because } \\
\text { of problems with your teeth, mouth or dentures? }\end{array}$ \\
\hline & 43 & $\begin{array}{l}\text { Have you had difficulty doing } \\
\text { your usual jobs because of } \\
\text { problems with your teeth, } \\
\text { mouth or dentures? }\end{array}$ & 41 & $\begin{array}{c}\text { ¿En el último mes ha tenido dificultad para interactuar } \\
\text { con otras personas debido a sus brackets? } \\
\text { In the last month have you had difficulty interacting } \\
\text { with other people because of your brackets? }\end{array}$ \\
\hline \multirow[t]{2}{*}{ Handicap } & 47 & $\begin{array}{l}\text { Have you felt that life in } \\
\text { general was less satisfying } \\
\text { because of problems with your } \\
\text { teeth, mouth or dentures? }\end{array}$ & 47 & $\begin{array}{c}\text { ¿En el último mes ha tenido la sensación que su vida } \\
\text { en general ha sido menos satisfactoria debido a sus } \\
\text { brackets? } \\
\text { In the last month you have had the feeling that your } \\
\text { life in general has been less satisfactory due to your } \\
\text { brackets? }\end{array}$ \\
\hline & 48 & $\begin{array}{l}\text { Have you been unable to } \\
\text { function because of problems } \\
\text { with your teeth, mouth } \\
\text { or dentures? }\end{array}$ & 46 & $\begin{array}{l}\text { ¿En el último mes ha sido incapaz de disfrutar de la } \\
\text { compañía de otras personas debido a sus brackets? } \\
\text { In the last month have you been unable to enjoy the } \\
\text { company of other people because of your brackets? }\end{array}$ \\
\hline
\end{tabular}

¿En el último mes ha sentido incomodidad al comer algunos alimentos debido a sus brackets?

In the last month have you felt discomfort when eating some foods due to your brackets?

¿En el último mes se ha sentido incomodo debido a

due to

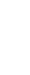

\section{.}




\section{OHIP-S14 Ortho Validation}

\subsection{Validity of the OHIP-S14 Ortho:}

Content validity was evaluated by an EFA, and the assumptions were previously verified (Bartlett sphericity test $\left.\left(X^{2}=981.003, P<0.0001\right), \mathrm{KMO}=0.863\right)$. Two factors were extracted, which accounted for $91.23 \%$ of the variance (Table 2). Construct validity assessed by the CFA model showed two latent dimensions (functional and social) from the OHIPS14 Ortho. Three bi-dimensional models were evaluated by the chi-squared value ( $\left.\chi^{2} / \mathrm{df}\right)$, AIC and TLI. The third model, with associations (Q4, Q46, Q1, Q15, Q34, Q22, Q23) and covariances between most of the items, was deemed best, as it had strong item loadings and a strong model fit $(A I C=3711.92 ; T L I=0.972$, $\chi 2 / d f=1.29, \mathrm{CFI}=0.981, \mathrm{RMSA}=0.049 ; \mathrm{SRMR}=0.037)$ (Table 5 and Annex 2).

Table 5. Confirmatory factor analysis (CFA) OHIP-S14 Ortho

\begin{tabular}{ccccccccccc}
\hline & Chi $^{2}$ & X²/df & RMSA & AIC & BIC & CFI & TLI & SRMR & $\begin{array}{c}\text { AVE } \\
\text { FUNC }\end{array}$ & $\begin{array}{c}\text { AVE } \\
\text { SOCIAL }\end{array}$ \\
\hline Model 1 & 223.33 & 2.93 & 0.125 & 3895.58 & 3946.85 & 0.84 & 0.813 & 0.075 & 0.51 & 0.517 \\
\hline Model 2 & 186.84 & 2.70 & 0.117 & 3803.09 & 3944.1 & 0.87 & 0.835 & 0.054 & 0.531 & 0.533 \\
\hline Model 3 & 77.67 & 1.29 & 0.049 & 3711.92 & 3878.31 & 0.981 & 0.972 & 0.037 & 0.507 & 0.513 \\
\hline
\end{tabular}

RMSEA (mean square error of approximation); AIC Akaike BIC information criterion (Bayesian information criterion); CFI (comparative adjustment index); TLI (Tucker-Lewis index); SRMR (Root square of the average of the sum of the squares of the residues); AVE (average variance extracted); FUNC (functional).

The mean scores of OHIP-S14 Ortho that showed statistically significant differences by sex were Q15, Q16, and Q42, with higher values in females. The questions with the highest negative impact on the OHRQoL were Q15 and Q16 (Figure 1).

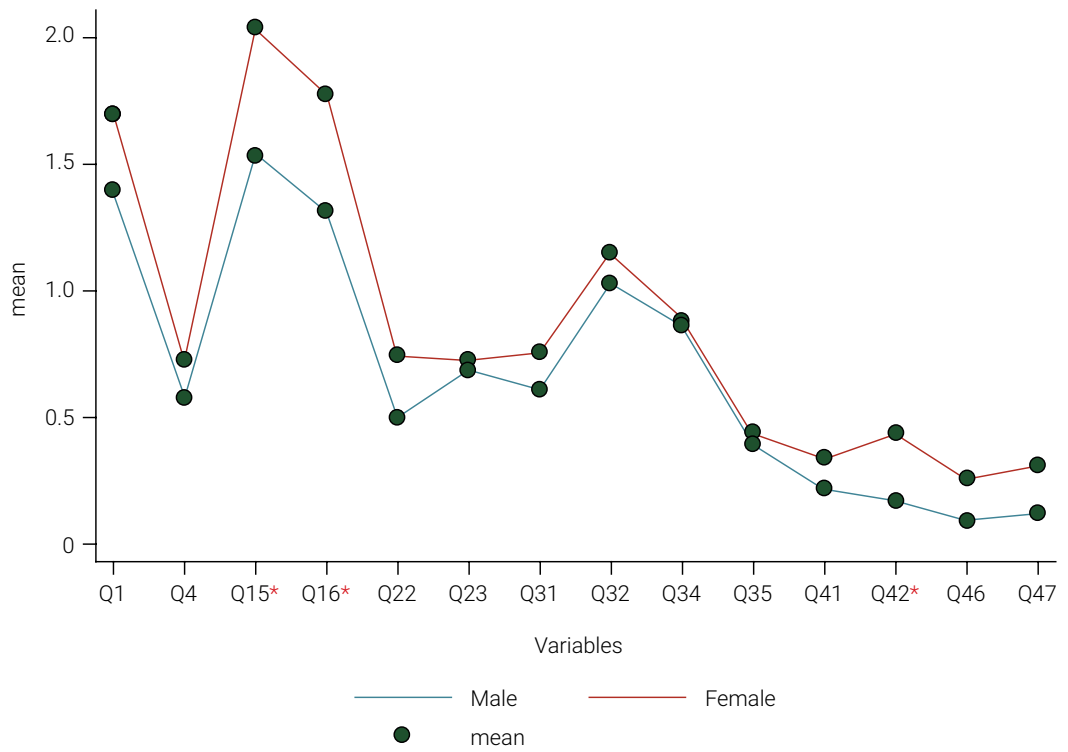

Figure 1. Mean scores of the OHIP-S14 Ortho questions by sex. 
Discriminative validity showed significantly $(P<0.05)$ higher OHIP-S14 Ortho scores in the intense pain perception group (19.56) than in the moderate (13.45) and mild (6.1) pain perception groups.

\subsection{Reliability of the OHIP-S14 Ortho:}

Internal consistency (Cronbach's a coefficient) for the OHIP-S14 Ortho was in total of $a=0.91$ (Annex 1). The intra-observer reliability assessment (test-retest) showed excellent correlation (Lin's correlation=0.80 $\pm 0.059 ; 95 \% \mathrm{Cl}: 0.68 ; 0.91$ ). The inter-observer agreement analysis showed a high correlation (Lin's correlation $=0.97 \pm 0.011$; 95\% Cl:0.68;0.91 and Spearman correlation coefficient=0.97).

\subsection{Sensitivity to change:}

The OHIP-S14 Ortho scores recorded at different time points were T0=2.64, SD $6.59, T 1=14, S D 10.27$, and $T 2=11.92$, SD 7.76, showing adequate sensitivity to change. There were significant differences $(P=0.001)$ between the OHIP-S14 Ortho scores at T0-T1 and T0-T2, but there were no differences between T1 and T2 $(P=0.0937)$ (Annex 3). Additionally, there was a 6.13-minute reduction in the scale administration time of the OHIP-S14 Ortho compared with that of the long form of the OHIP.

\section{Discussion}

\section{OHIP-S14 Ortho Development}

According to our results, a version of OHIP-14 was extracted for subjects with fixed orthodontic appliances. The OHIP-S14 Ortho had eight items that were different from those in the original short-form OHIP developed by Slade ${ }^{22}$. Two were from the functional limitation dimension (Q1: difficulty chewing, Q4: "appearance affected"), and six were from each of the other six dimensions (Q16: "sore spots", Q22: "appearance", Q31: “avoid smiling", Q34: "upset”, Q41: "trouble getting on with others", and Q46: "unable to enjoy people's company").

Compared with the OHIP-S14 Ortho, a different version in Spanish developed by Castrejón-Perez and Borges-Yañez ${ }^{9}$ had seven different items, and another version in Spanish developed by León et al. ${ }^{13}$ did not have any matching items. Likewise, other short forms of the OHIP derived by other authors ${ }^{8,23-26}$ differ from the original shortform OHIP derived by Slade ${ }^{22}$. The differences might be explained by the cultural distinctiveness of the populations studied, the short-form development methodologies, or the specific impact that fixed orthodontic appliances have on the subject. The OHIP's versions mentioned were about populations with dental needs other than patients wearing fixed orthodontic appliances. Fixed orthodontic appliances affect functional and physical dimensions, making it difficult to consume certain hard and sticky foods, which can cause pain or damage to the appliance. They can also affect appearance, which can generate a social impact on the daily life of patients, preventing them from smiling, and participating in social activities ${ }^{27,28}$. 
One important aspect to be considered is the different statistical methods used to derive the different OHIP short forms. In our study, we used the statistical methods suggested by Slade and Spencer ${ }^{6}$ that were also applied by León et al. ${ }^{13}$, (reliability analysis, principal component factor analysis, and least squares regression analysis), whereas other studies used a statistically significant association about the clinical variables ${ }^{9}$, the item frequency method ${ }^{8}$, or EFA ${ }^{29}$. The sample's age range is another important factor to consider. Most of the studies were conducted with subjects older than 60 years ${ }^{9,13,22}$ who had oral rehabilitation needs, while the sample in our research mainly included patients over 11 years old, as adolescents and young adults mostly represent the population undergoing orthodontic treatment.

OHIP specifically evaluates problems with the mouth, teeth, or dentures, as proposed by Slade and Spencer ${ }^{6}$. However, as shown by the results of this study, the scale can be adapted by an appropriate method to another target population, such as patients undergoing orthodontic treatment. Likewise, the scale can be adapted to assess the impact on OHRQoL in the last month, which, in patients with orthodontic treatment, accounts for the most recent impact of orthodontic treatment, whereas, with the original OHIP-496,22,30, it was assessed over the previous year.

The two items from each dimension from the original OHIP were maintained in the OHIP 14 S-Ortho. Also, the high Cronbach's alpha (0.912) indicates that the scale measures the same construct. Therefore, we suggest that this number of items satisfactorily evaluates the OHRQoL construct for orthodontic patients ${ }^{31}$.

\section{OHIP-S14 Ortho Validation}

This study demonstrated appropriate validity of the OHIP-S14 Ortho scale across two main dimensions (functional limitation and social disability) and the associations and covariances between all the items. Santos et al. ${ }^{32}$ compared one-dimensional and tri-dimensional structures of the OHIP-14 and reported that the scale measures one single construct. John et al. ${ }^{33}$ compared the psychometric performance of three models: a unidimensional model, a four-factor model, and a bifactor model, showing that the model with the best fit was the four-factor model. However, the other two models also showed a good fit, suggesting that one OHIP summary score is sufficient to characterize OHRQOL.

The OHIP-S14 Ortho showed excellent discriminative validity compared with the Visual Analog Scale for Pain (VAS Pain). Other authors used clinical variables such as periodontal status, caries, or missing teeth to evaluate the discriminative validity ${ }^{8-11,13,22}$ because these variables affect OHRQoL. Moreover, in orthodontic patients, oral health must be at an optimum level to initiate tooth movement. Pain and discomfort occur as part of orthodontic mechanotherapy, but it is an individual and subjective response dependent on factors such as age, sex, individual pain thresholds, the magnitude of the force applied, the current emotional state and stress, cultural differences, and previous pain experiences ${ }^{27}$. Thus, this research allows clinicians to improve communication with patients so that they can plan treatment and use the OHIP-S14 Ortho in daily practice. 
According to the reliability results, the OHIP-S14 Ortho indicated to have very good internal consistency (Cronbach's a coefficient $=0.912$ ), a good level of test-retest agreement (Lin's=0.80; ICC=0.894), and inter-observer agreement (Lin's=0.97; Spearman=0.97). Similar results were reported in other studies ${ }^{9,13,33}$.

The scale also demonstrated good sensitivity to change in the initial stages of orthodontic treatment, showing that the OHIP-S14 Ortho has a good capacity to respond to changes in the OHRQoL that occur during orthodontic treatment, but more extensive testing of the measure's responsiveness to change needs to be carried out to confirm this statement. Although in previous studies ${ }^{8-10,12,13,22}$ sensitivity to change has not been evaluated, it is important to measure the impact of orthodontic treatment on OHRQoL over time. Mansor et al. ${ }^{5}$, found that OHRQoL became highly deteriorated within 24 hours after the placement of fixed orthodontic appliances. Streiner ${ }^{19}$ and Johal et al. ${ }^{28}$ determined that the initial stages of fixed appliance treatment result in a negative impact on the quality of life and pain experience but that pain and discomfort intensity significantly decrease three days after the bracket's placement and over the following three months. In our study, Q15 (eating discomfort) and Q16 (painful sites in the mouth) had a higher negative impact on the OHRQOL, suggesting that pain and discomfort are the main impact during orthodontic treatment. To assess the impact on OHRQoL in a wide range of time wearing fixed orthodontic appliances since discomfort is experienced in the first 24 hours after brackets placement and subsequent adjustment visits ${ }^{5,19,28}$. However, this assessment could be a limitation due to the inaccuracy which is derived from this aspect, so future research with homogeneous ranges of time of wearing fixed orthodontic appliances is recommended.

Within the limitations of the current study, the data did not show ceiling effects, as the maximum score of 56 of the OHIP-14 scale was not reported by any of the participants. Meanwhile, there were floor effects (scores of 0 ), which might suggest that the questionnaire is not picking up all the potential impacts of a fixed appliance, and it might be helpful to implement further qualitative work to determine this.

Kettle et al. ${ }^{34}$ identified from young people a multi-dimensional social process of managing everyday life with an orthodontic appliance. This study only included subjects wearing buccal fixed appliances; therefore, the impact of other removable appliances, retainers, or lingual brackets was not measured with the OHIP-S14 Ortho, and the results are not generalizable to all kinds of orthodontic treatment. Although the original OHIP-14 version was derived from adult patients, in orthodontics, it has been widely used with patients under 18 years of age ${ }^{5,28}$ as it was with our study; however, it would be more appropriate to use the OHIP-14 with individuals' questionnaires developed for young people as is the Child Oral Health Impact Profile (COHIP) $)^{35}$. In our results, both OHIP-49 and OHIP-S14 Ortho total scores were higher in adult patients ( $\geq 18$ years old) than in younger patients, suggesting a different impact in the OHRQOL according to age. Further research considering important variables that were not examined in this study, such as socioeconomic status and psychological parameters (self-esteem, depression, and stress), must be done.

Regarding the usefulness of the OHIP-14 scale, in our study, the time to completion of the long-form OHIP was 8.93 minutes, while for the OHIP-S14 Ortho, it was 2.8 
minutes. This shows that there was a significant decrease in the time to completion of the questionnaire. Currently, people's time and their compliance with surveys are very important; therefore, long-form questionnaires must be avoided. However, other authors have suggested that reducing the number of questions in the instrument can affect their psychometric properties and that an excessive simplification of the scale can lead to negative interpretations ${ }^{7}$. Conversely, other studies ${ }^{3,31}$ have suggested that a reduction in the number of questions does not affect the responsiveness of the instrument, but it does affect its validity and reliability.

Another factor to take into account is the response scale used in this study. Although it is easily quantifiable and understood, it might not measure the true attitudes of respondents, which could underestimates the effects of impacts of high concern to individuals, as the impact of the malocclusion is largely in the emotional and social well-being subscales ${ }^{34}$.On the other hand, our study analysis approach was by classical test theory (CTT) instead of the item response theory (IRT), based on the notion that CTT does not invoke a complex theoretical model to relate an examinee's ability to succeed on a particular item and that is easier to apply in many testing situations. However, readers must be aware of the weakness of CTT in terms of its circular dependency on item/person statistics.

As the conclusions of the present study, the OHIP-S14 Ortho is a valid and reliable instrument to measure OHRQoL in Spanish-speaking patients with fixed orthodontic appliances, and the construct validity of the OHIP-S14 Ortho showed a two-dimensional structure with associations and covariances between all the items.

Ethics statement: Individuals who were wearing fixed orthodontic appliances were provided by the UniCIEO University in Bogotá, Colombia. This study was approved by the UniCIEO University Ethics Committee.

Conflicts of interest: None.

\section{References}

1. Sischo L, Broder HL. Oral health-related quality of life: what, why, how, and future implications. J Dent Res. 2011 Nov;90(11):1264-70. doi: 10.1177/0022034511399918.

2. Bernabé E, Sheiham A, Tsakos G, Messias C. The impact of orthodontic treatment on the quality of life in adolescents: A case-control study. Eur J Orthod. 2008 Oct;30(5):515-20. doi: 10.1093/ejo/cjn026.

3. Andiappan M, Gao W, Bernabé E, Kandala N-B, Donaldson AN. Malocclusion, orthodontic treatment, and the Oral Health Impact Profile (OHIP-14): Systematic review and meta-analysis. Angle Orthod. 2015 May;85(3):493-500. doi: 10.2319/051414-348.1.

4. Johal A, Alyaqoobi I, Patel R, Cox S. The impact of orthodontic treatment on quality of life and selfesteem in adult patients. Eur J Orthod. 2015 Jun;37(3):233-7. doi: 10.1093/ejo/cju047.

5. Mansor N, Saub R, Othman SA. Changes in the oral health-related quality of life $24 \mathrm{~h}$ following insertion of fixed orthodontic appliances. J Orthod Sci. 2012 Oct;1(4):98-102. doi: 10.4103/2278-0203.105880.

6. Slade GD, Spencer AJ. Development and evaluation of the oral health impact profile. Community Dent Health. 1994 Mar;11(1):3-11. 
7. Locker D, Allen PF. Developing short form measures of oral health related quality of life. J Public Health Dent. 2002;62(1):13-20. doi: 10.1111/j.1752-7325.2002.tb03415.x.

8. Saub R, Locker D, Allison P. Derivation and validation of the short version of the malaysian oral health impact profile. Community Dent Oral Epidemiol. 2005 Oct;33(5):378-83. doi: 10.1111/j.1600-0528.2005.00242.x.

9. Castrejón-Pérez RC, Borges-Yáñez SA. Derivation of the short form of the Oral Health Impact Profile in Spanish (OHIP-EE-14). Gerodontology. 2012 Jun;29(2):155-8. doi: 10.1111/j.1741-2358.2012.00613.x.

10. Corridore D, Campus G, Guerra F, Ripari F, Sale S, Ottolenghi L, et al. Validation of the Italian version of the Oral Health Impact Profile-14 ( IOHIP-14 ). Ann Stomatol (roma). 2014 Feb 4;4(3-4):239-43.

11. Papagiannopoulou V, Oulis C, Papaioannou W, Antonogeorgos G, Yfantopoulos J. Validation of a Greek version of the oral health impact profile (OHIP-14) in adolescents. Eur Arch Paediatr Dent. 2010 Oct;11(5):247-52. doi: 10.1007/BF03262756.

12. Montero J, Bravo M, Albaladejo A, Hernández LA, Rosel EM. Validation the Oral Health Impact Profile (OHIP-14sp) for adults in Spain. Med Oral Patol Oral Cir Bucal. 2009 Jan 1;14(1):E44-50.

13. León S, Bravo D, Correa G, Giacaman R. Validation of the Spanish version of the Oral Health Impact Profile (OHIP-14Sp) in elderly Chileans. BMC Oral Health. 2014 Aug;14:95. doi: 10.1186/1472-6831-14-95.

14. Petersen PE. The World Oral Health Report 2003: continuous improvement of oral health in the 21 st century--the approach of the WHO Global Oral Health Programme. Community Dent Oral Epidemiol. 2003 Dec;31 Suppl 1:3-23. doi: 10.1046/j..2003.com122.x.

15. Rahman S, Spencer RJ, Littlewood SJ, O'Dywer L, Barber SK, Russell JS. A multicenter randomized controlled trial to compare a self-ligating bracket with a conventional bracket in a UK population. Part 2: pain perception. Angle Orthod. 2016 Jan;86(1):149-56. doi: 10.2319/112414-838.1.

16. Miller KB, McGorray SP, Womack R, Quintero JC, Perelmuter M, Gibson J, et al. A comparison of treatment impacts between Invisalign aligner and fixed appliance therapy during the first week of treatment. Am J Orthod Dentofacial Orthop. 2007 Mar;131(3):302.e1-9. doi: 10.1016/j.ajodo.2006.05.031.

17. Jian F, Lai W, Furness S, Gt M, Dt M, Hickman J, et al. Initial arch wires for tooth alignment during orthodontic treatment with fixed appliances. Cochrane Database Syst Rev. 2013 Apr 30;2013(4):CD007859. doi: 10.1002/14651858.CD007859.pub3.

18. Johal A, Ashari AB, Alamiri N, Fleming PS, Qureshi U, Cox S, et al. Pain experience in adults undergoing treatment: a longitudinal evaluation. Angle Orthod. 2018 May;88(3):292-8. doi: 10.2319/082317-570.1.

19. Streiner DL. Figuring out factors: The use and misuse of factor analysis. Can J Psychiatry. 1994 Apr;39(3):135-40. doi: 10.1177/070674379403900303.

20. World Health Organization: Process of translation and adaptation of instruments. WHO; 2007 [cited 2020 Aug 25]. Available from: https://www.who.int/substance_abuse/research_tools/ translation/en.

21. Marôco, J. [Structural equations analysis: Theoretical foundations, software \& applications]. Pêro Pinheiro: ReportNumber; 2010. Portuguese.

22. Slade GD. Derivation and validation of a short-form oral health impact profile. Community Dent Oral Epidemiol. 1997 Aug;25(4):284-90. doi: 10.1111/j.1600-0528.1997.tb00941.x.

23. John MT, Miglioretti DL, LeResche L, Koepsell TD, Hujoel P, Micheelis W. German short forms of the Oral Health Impact Profile. Community Dent Oral Epidemiol. 2006 Aug;34(4):277-88. doi: 10.1111/j.1600-0528.2006.00279.x. 
24. Wong MCM, Lo ECM, MCMillan AS. Validation of a Chinese version of the Oral Health Impact Profile (OHIP). Community Dent Oral Epidemiol. 2002 Dec;30(6):423-30. doi: 10.1034/j.1600-0528.2002.00013.x.

25. Bae K-H, Kim H-D, Jung S-H, Park D-Y, Kim J-B, Paik D-I, et al. Validation of the Korean version of the oral health impact profile among the Korean elderly. Community Dent Oral Epidemiol. 2007 Feb;35(1):73-9. doi: 10.1111/j.1600-0528.2007.00331.x.

26. Yamazaki M, Inukai M, Baba K, John Mt. Japanese version of the Oral Health Impact Profile (OHIP-J). J Oral Rehabil. 2007 Mar;34(3):159-68. doi: 10.1111/j.1365-2842.2006.01693.x.

27. Krishnan V. Orthodontic pain: from causes to management--a review. Eur J Orthod. 2007 Apr;29(2):170-9. doi: 10.1093/ejo/cjl081.

28. Johal A, Fleming PS, Al Jawad FA. A prospective longitudinal controlled assessment of pain experience and oral health-related quality of life in adolescents undergoing fixed appliance treatment. Orthod Craniofac Res. 2014 Aug;17(3):178-86. doi: 10.1111/ocr.12044.

29. Campbell D, Fiske D. Convergent and discriminant validation by the multitrait-multimethod matrix. Psychol Bull. 1959 Mar;56(2):81-105.

30. Lopez R, Baelum V. Spanish version of the Oral Health Impact Profile (OHIP-Sp). BMC Oral Health. 2006 Jul;6:11. doi: 10.1186/1472-6831-6-11.

31. Awad M, Al-Shamrany M, Locker D, Allen F, Feine J. Effect of reducing the number of items of the Oral Health Impact Profile on responsiveness, validity and reliability in edentulous populations. Community Dent Oral Epidemiol. 2008 Feb;36(1):12-20. doi: 10.1111/j.1600-0528.2006.00364.x.

32. Santos C, Branca H, Nadanovsky P, Balbinot J, Keller R, Neves F. The Oral Health Impact Profile-14: a unidimensional scale? Cad Saude Publica. 2013 Apr;29(4):749-57. doi: 10.1590/s0102-311×2013000800012.

33. John MT, Feuerstahler L, Waller N, Baba K, Larsson P, Čelebić A, et al. Confirmatory factor analysis of the oral health impact profile. J Oral Rehabil. 2014 Sep;41(9):644-52. doi: 10.1111/joor.12191.

34. Kettle JE, Hyde AC, Frawley T, Granger C, Longstaff SJ, Benson PE. Managing orthodontic appliances in everyday life: A qualitative study of young people's experiences with removable functional appliances, fixed appliances and retainers. J Orthod. 2020 Mar;47(1):47-54. doi: $10.1177 / 1465312519899671$.

35. Broder HL, McGrath C, Cisneros GJ. Questionnaire development: face validity and item impact testing of the Child Oral Health Impact Profile. Community Dent Oral Epidemiol. 2007 Aug;35 Suppl 1:8-19. doi: 10.1111/j.1600-0528.2007.00401.x. 
Annex 1. Reliability: Cronbach's alpha values for OHIP-49 and OHIP-S14 Ortho

\begin{tabular}{|c|c|c|c|c|c|}
\hline \multicolumn{6}{|c|}{ OHIP-49 } \\
\hline $\begin{array}{l}\text { Questio } \\
\text { n }\end{array}$ & Item & Cronbach's $\alpha$ & Question & Item & Cronbach's $\alpha$ \\
\hline Q1 & Difficulty chewing & 0.93 & Q27 & Unable to brush your teeth & 0.93 \\
\hline Q2 & Difficulty pronouncing words & 0.93 & Q28 & Avoid eating & 0.93 \\
\hline Q4 & Affected appearance & 0.93 & Q29 & Unsatisfactory diet & 0.93 \\
\hline Q5 & Bad breath & 0.93 & Q30 & Unable to eat & 0.93 \\
\hline Q6 & Worsened taste & 0.93 & Q31 & Avoid smiling & 0.93 \\
\hline Q7 & Stuck food & 0.93 & Q32 & Interrupting meals & 0.93 \\
\hline Q8 & Worsened Digestion & 0.93 & Q33 & Interrupting sleep & 0.93 \\
\hline Q9 & Pain due to wounded mouth & 0.93 & Q34 & Annoyed & 0.93 \\
\hline Q10 & Discomfort in the jaw & 0.93 & Q35 & Difficulty to relax & 0.93 \\
\hline Q11 & Headaches & 0.93 & Q36 & Depressed & 0.93 \\
\hline Q12 & Sensitive teeth & 0.93 & Q37 & Affected attention & 0.93 \\
\hline Q13 & Pain in their teeth & 0.93 & Q38 & Ashamed & 0.93 \\
\hline Q14 & Pain in your gums & 0.93 & Q39 & Avoid leaving & 0.93 \\
\hline Q15 & Discomfort when eating & 0.93 & Q40 & Less tolerant with others & 0.93 \\
\hline Q16 & Painful sites in the mouth & 0.93 & Q41 & Interact with others & 0.93 \\
\hline Q19 & Worried & 0.93 & Q42 & Irritable with others & 0.93 \\
\hline Q20 & Self-conscious & 0.93 & Q43 & Difficulty working & 0.93 \\
\hline Q21 & Unhappy & 0.93 & Q44 & General Health Affected & 0.93 \\
\hline Q22 & Appearance of the brackets & 0.93 & Q45 & Financial loss & 0.93 \\
\hline Q23 & Tense & 0.93 & Q46 & Enjoy company & 0.93 \\
\hline Q24 & Speaking badly & 0.93 & Q47 & Unsatisfactory life & 0.93 \\
\hline Q25 & People do not understand their words & 0.93 & Q48 & Unable to function & 0.93 \\
\hline Q26 & Less flavor in food & 0.93 & Q49 & Unable to work & 0.93 \\
\hline Total & & & & & 0.93 \\
\hline \multicolumn{6}{|c|}{ OHIP-S14 Ortho } \\
\hline Q1 & Difficulty chewing & 0.91 & Q32 & Interrupting meals & 0.91 \\
\hline Q4 & Affected appearance & 0.90 & Q34 & Annoyed & 0.90 \\
\hline Q15 & Discomfort when eating & 0.90 & Q35 & Difficulty to relax & 0.91 \\
\hline Q16 & Painful sites in the mouth & 0.90 & Q41 & Interact with others & 0.91 \\
\hline Q22 & Appearance of the brackets & 0.91 & Q42 & Irritable with others & 0.91 \\
\hline Q23 & Tense & 0.91 & Q46 & Enjoy company & 0.91 \\
\hline Q31 & Avoid smiling & 0.91 & Q47 & Unsatisfactory life & 0.91 \\
\hline Total & & & & & 0.91 \\
\hline
\end{tabular}


Annex 2. Association between OHIP-49, OHIP- S14 Ortho and demographic and clinical characteristics

\begin{tabular}{|c|c|c|}
\hline Categorical Variables & $\begin{array}{l}\text { OHIP-49 } \\
\text { Mean (ds) }\end{array}$ & $\begin{array}{c}\text { OHIP-S14 Ortho } \\
\text { Mean (ds) }\end{array}$ \\
\hline \multicolumn{3}{|l|}{ Sex } \\
\hline Male & $24.89(18.84)$ & $7.53(6.84)$ \\
\hline Female & $27.72(20.07)$ & $9.16(8.0)$ \\
\hline P value & 0.120 & 0.059 \\
\hline \multicolumn{3}{|l|}{ Occupation } \\
\hline Unemployed & $25.92(27.09)$ & $7.65(9.26)$ \\
\hline Independent worker & $29.92(27.09)$ & $9.78(7.89)$ \\
\hline Employee & $27.21(19.71)$ & $8.70(7.97)$ \\
\hline Depend on family resources & $24.04(17.42)$ & $7.45(6.39)$ \\
\hline Pvalue & 0.132 & 0.077 \\
\hline \multicolumn{3}{|l|}{ Education level } \\
\hline Primary School & $28.67(20.45)$ & $9.17(6.71)$ \\
\hline Middle school & $23.39(15.10)$ & $6.35(5.72)$ \\
\hline High school & $22.73(19.10)$ & $7.37(7.52)$ \\
\hline Post-secondary education & $26.71(12.10)$ & $8.14(3.63)$ \\
\hline Technical education & $25.85(18.08)$ & $8.02(6.65)$ \\
\hline University education & $30.69(22.92)$ & $10.34(9.06)$ \\
\hline Specialization Course/Master & $27.35(16.59)$ & $8.65(6.55)$ \\
\hline Doctoral degree & $12(4.24)$ & $4.5(0.719)$ \\
\hline$P$ value & 0.190 & 0.128 \\
\hline \multicolumn{3}{|l|}{ Orthodontic Technique } \\
\hline Standard & $25.62(17.62)$ & $7.81(6.54)$ \\
\hline Self-ligating & $27.54(20.55)$ & $9.40(8.55)$ \\
\hline MBT & $26.60(20.65)$ & $8.33(7.70)$ \\
\hline$P$ value & 0.889 & 0.558 \\
\hline Age & 0.099 & 0.125 \\
\hline Pvalue & 0.048 & 0.013 \\
\hline Last Control Time & -0.092 & -0.062 \\
\hline$P$ & 0.067 & 0.216 \\
\hline Treatment Time & -0.004 & -0.062 \\
\hline$P$ & 0.937 & 0.216 \\
\hline
\end{tabular}

$\mathrm{Chi}^{2}$ test for categorical variables and independent t-test for quantitative variables 
Annex 3.

FCA model 1.

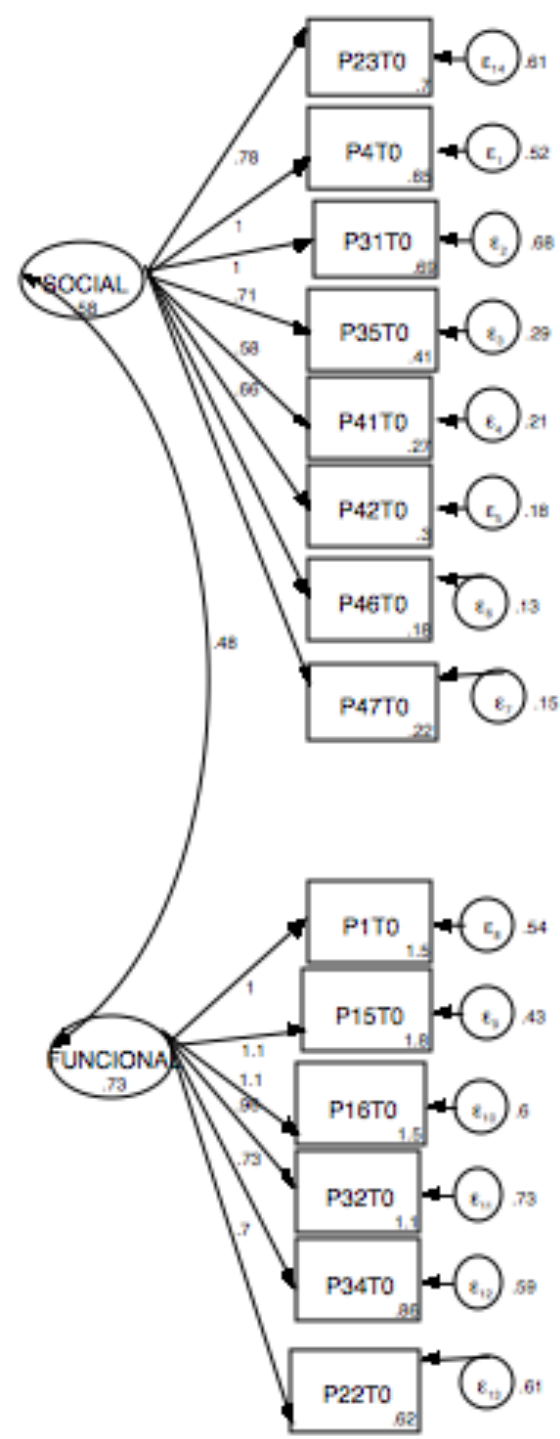




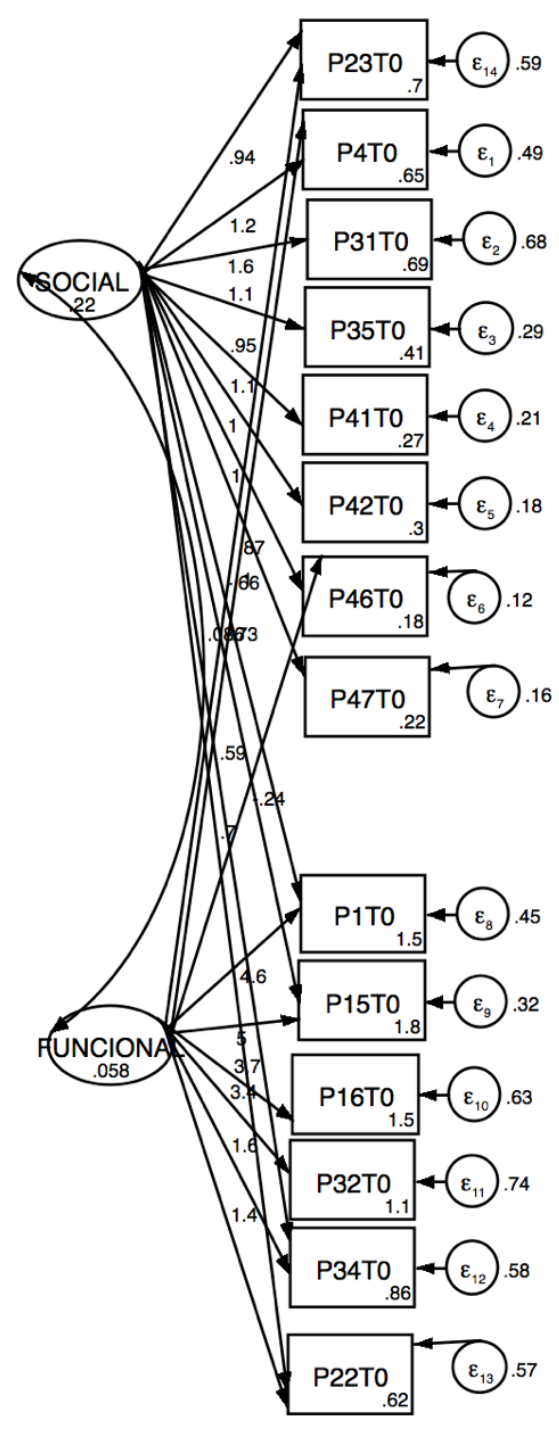

FCA model 2. 


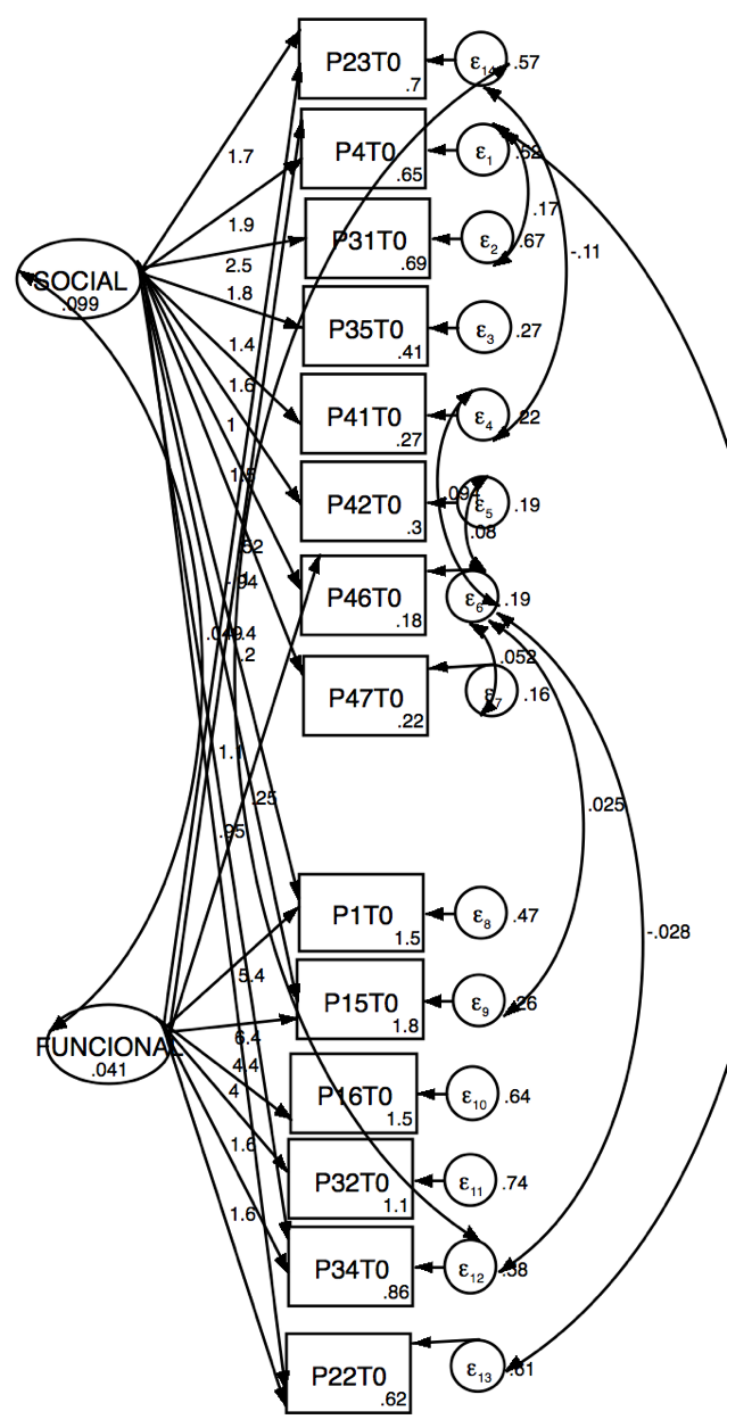

FCA model 3. 
Annex 4. Sensitivity to change. Mean (sd).

\begin{tabular}{|c|c|c|c|c|c|c|}
\hline & T0 & $\mathrm{T} 1$ & $\mathrm{~T} 2$ & T0- T1 & $\mathrm{T} 0-\mathrm{T} 1$ & $\mathrm{~T} 1-\mathrm{T} 2$ \\
\hline Mean & $2.64(6.59)$ & $14(10.27)$ & $11.92(7.76)$ & $0.001^{\mathrm{a}}$ & $0.001^{\mathrm{a}}$ & $0.0937^{\mathrm{a}}$ \\
\hline
\end{tabular}

